\title{
Cocoa Farmers and their Perceptions of Climate Change: A Case Study of the Central and Western Regions of Ghana
}

\author{
Dr. David NiiBaah Buxton ${ }^{1 *}$, Dr. Benjamin L. Lamptey ${ }^{2}$, Dr. Benjamin Kofi Nyarko ${ }^{3}$ \\ ${ }^{I}$ Department of Geography and Regional Planning, University of Cape Coast, Cape Coast, Ghana \\ ${ }^{2}$ African Center of Meteorological Applications for Development (ACMAD), 55 Avenue des Ministries, BP \\ 13184, Niamey, Niger \\ ${ }^{3}$ Department of Geography and Regional Planning, University of Cape Coast, Cape Coast \\ Ghana
}

*Corresponding Author: Dr. David NiiBaah Buxton, Department of Geography and Regional Planning, University of Cape Coast, Cape Coast, Ghana.

\begin{abstract}
Adaptation to climate change requires that farmers first notice that the climate has changed, identify useful adaptations and implement them. One factor that has been most often left out is the issue of perception. How can one adapt to climate change in an adequate way if one does not perceive current and future climate change as a reality? It is arguable that the first step towards adaptation is the perception of the problem.
\end{abstract}

A systematic and integrated methodology was used to collect data for analysis. A field survey in some cocoa growing communities in the Central and Western regions of Ghana was conducted between July 2013 and February, 2014.

Rainfall was the most significant climatic parameter. Long dry periods, unpredictable rainfall patterns and high sunshine/temperatures were among the noticeable changes in climate. Gender, education, farming experience, and exposure to the mass media among other factors had a positive and significant relationship with farmer perceptions of climate change.

Farmers who perceive a change in climate are more likely to adapt to reduce the impact on their production. In designing adaptation strategies and communicating them to farmers, the perceptions of farmers and the factors affecting them cannot be ignored.

\section{INTRODUCTION}

Adaptation to climate change requires that farmers first notice that the climate has changed, identify useful adaptations and implement them [1]. According to the 2001 report of the Intergovernmental Panel on Climate Change (IPCC), adaptation has the potential to reduce adverse effects of climate change. Hence there is the need for a good understanding of adaptation potentials and the limitations as pointed out by the IPCC. Current studies have tended to focus on financial, technical and institutional considerations to evaluate the adaptive capacity of a population. One factor that has been conspicuously left out is the issue of perception. The question is how can one adapt to climate change in an adequate way if one does not perceive climate change as a reality now and in the future? It is arguable, therefore, that the first step towards adaptation is to perceive the problem.

Bartley (1969)[2], states that perception is the immediate discriminatory response of an organism to energy activating sense organs. Forgus (1966)[3], also adds that perception is the process by which an organism receives or extracts certain information about the environment.

Similarly, Barnhart (1988)[4], explains that perception is the state of being aware of something through the senses, that is: of seeing, hearing, tasting, smelling and feeling. It also involves insights, apprehension, discrimination and comprehension. 
Therefore, the word perception as used in this paper is the reaction of cocoa farmers to a phenomenon (climate change) in their environment. It is the way cocoa farmers use their senses to discern or recognize that the climate has changed and is still changing.

One global issue concerning climate change and its effect on agriculture is whether farmers have the ability to perceive the change in climate that has already occurred. Farmers need to understand global climate and how it is changing in order to take appropriate initiatives to combat its effect on their production. This paper describes cocoa farmers' perception to climate change and some factors that influence their perception.

\section{Methodology}

\subsection{Study Area}

Ghana's cocoa belt lies in the south of the country, figure 1. The Central and Western Regions, were covered in the survey. These areas represent a cross-section of the geographical variation in the cocoa belt. Some parts of the Central Region, has been a traditional cocoa-growing area, whilst Western Region is a new area of production. The AssinFoso cocoa district in the Central region and the SewfiBoako and Sekondi-Takoradi cocoa districts, both in the Western Region, were used for the study. The soils (Figure 2) in these areas fall under the suitable to highly suitable cocoa soil classification of Adu and Mensah-Ansah (1969)[5].

The AssinFoso cocoa district lies within Longitudes $1^{\circ} 05^{\prime}$ East and $1^{\circ} 25^{\prime}$ West and Latitudes $6^{\circ} 05^{\prime}$ North and $6^{\circ} 40^{\prime}$ South. The Assin North District falls within the moist tropical, mainly deciduous forest. The area has an annual rainfall between 1500 and $2000 \mathrm{~mm}$. Annual temperatures are high and range between $30^{\circ} \mathrm{c}$ in March/April and about $26^{\circ} \mathrm{c}$ in August. Average relative humidity is high, ranging from $60 \%$ to $70 \%$.

The Sekondi-Takoradi cocoa district is characterized by an equatorial climate. Temperatures are high, with an average of 22 degrees Celsius. It has a mean annual rainfall of 2,350 millimetres, which is experienced heavily in May and June, with the minor rains occurring between September and October. The climate offers opportunities for varying agricultural production. The vegetation is mainly woodland in the northern and central parts. In areas where there are no permanent crops, especially along the coast, thickets are interspersed with tall grass species. The SefwiBoako cocoa district falls within the tropical rainforest climatic zone, with high temperatures between $25^{\circ} \mathrm{C}$ and $30^{\circ} \mathrm{C}$ throughout the year. It has a moderate to heavy rainfall between $1524 \mathrm{~mm}$ and $1780 \mathrm{~mm}$ per annum, with double maxima characteristics in June to July and September to October. Humidity is relatively high, about 90 per cent at night, falling to 75 per cent during the day. There are two long wet seasons, separated by a short relatively dry season.

The objective of this paper is to discuss the perception of cocoa farmers of changes in climate. To do this, a systematic and integrated methodology was used to collect data for analysis. A field survey in some cocoa growing communities in the Central and Western regions of Ghana was conducted between July 2013 and February, 2014. Qualitative methods such as participatory diagnostic tools informal semi-structured and formal structured surveys based on individual interviews, and key informant interviews of some selected farmers and other stakeholders were used to comprehend and describe perceptions of cocoa farmers of climate change. Other socio-demographic information was collected to assess factors that may affect the perception of the farmers. Altogether, 444 cocoa farmers were chosen from 29 communities in the Central and Western Regions. Only farmers who had been in the occupation for 10 years and over were interviewed, on the assumption that they had more experience on climate change observations. The data collected were tabulated and statistically analyzed to interpret the results. Descriptive statistics were used to describe farmers' perception of climate change. 


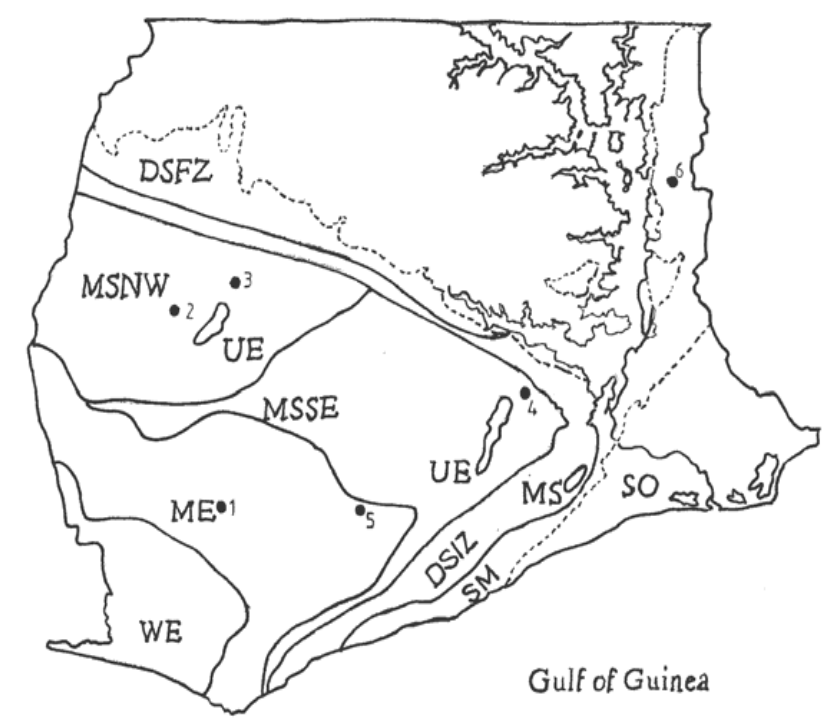

Figure1.Forest Zones which Support Cocoa Production in Ghana

Source: Anim-Kwapong and Frimpong, (2005)

KEY:Forest boundaries shown by broken line (----). Forest-type abbreviations: WE=Wet Evergreen; $U E=U p l a n d$ Evergreen; ME=Moist Evergreen; MS=Moist Semi-deciduous (NW=Northwest subtype; SE=Southeast subtype); DS Dry Semi-deciduous (FZ=Fire Zone subtype; IZ=Inner Zone subtype; SM=Southern Marginal; $S O=$ Southern Outliners
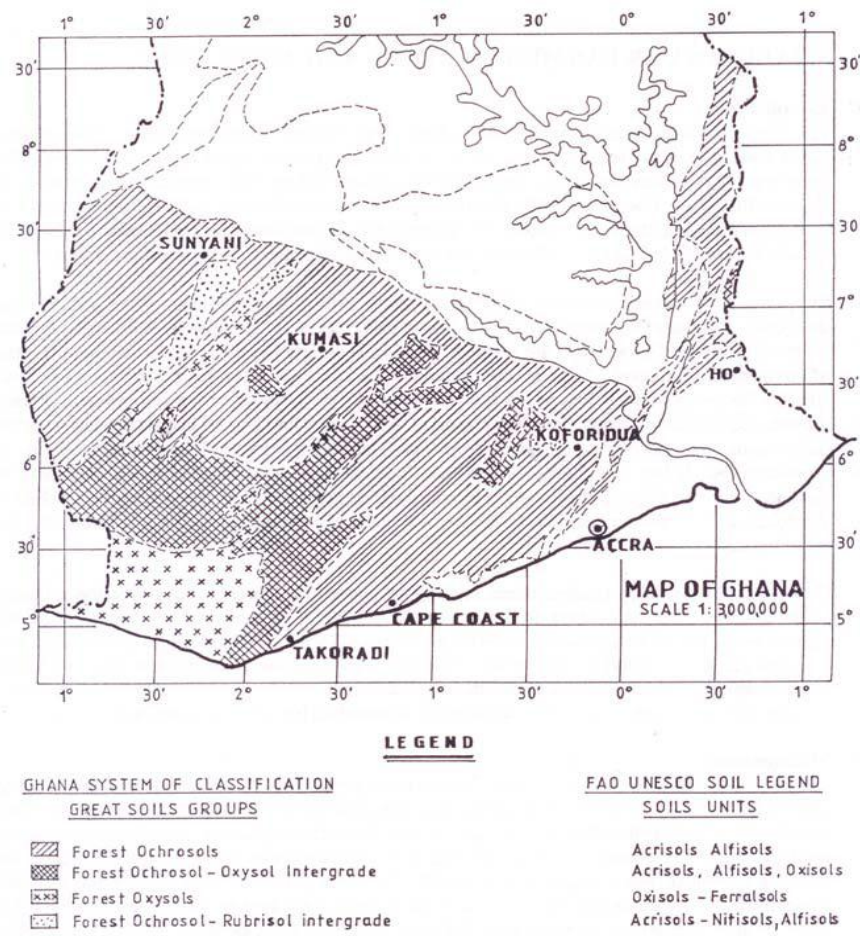

Figure2.The Major Soil Groups within the Cacao Growing Regions in Ghana.

Source: Adu and Mensah-Ansah (1969)

\section{RESULTS AND DISCUSSION}

Although most of the farmers interviewed do not understand the science and concept of climate change, their observations on the effects of decreasing rainfall, increasing air temperature, increasing 
sunshine intensity and seasonal changes in the onset, duration, intensity and frequency of rainfall are very impressive.

\subsection{Assessing Farmer Perceptions to Climate Change}

The selected 444 respondents were interviewed personally with the help of a well- structured and pretested interview schedule. Data collected focused on farm history, memory of extreme climate events and the impact of more frequent anomalies and management responses to those anomalies. The data thus collected have been tabulated and statistically analyzed to interpret the results. Descriptive statistics have been used to characterize farmer perceptions of climate changes.

First of all, farmers were asked which of the climatic elements, according to them, was most important to cocoa production. They were asked to rank the elements in order of importance, giving the most important element the number 5. The responses of the farmers are shown in Table 1 below.

Table1.Most important climatic element for cocoa production

\begin{tabular}{|l|l|l|l|}
\hline Rank & Most important Element & Frequency & Percentage \\
\hline 5 & Rainfall & 404 & $91 \%$ \\
\hline 4 & Sunshine & 334 & $75 \%$ \\
\hline 3 & Temperature & 174 & $39 \%$ \\
\hline 2 & Humidity & 185 & $42 \%$ \\
\hline 1 & Wind & 203 & $46 \%$ \\
\hline
\end{tabular}

Source: Field Survey, 2013.

Significantly, $404(91 \%)$ of the respondents stated that rainfall was the most important desirable element for cocoa production. The next important desirable element, identified by $334(75 \%)$ of the farmers interviewed was sunshine. Wind was the least desired element, according to 203 (46\%) of the farmers used for the study. According to them, it led to losses, especially during the flowering and early fruiting stages of production.

Farmers were then asked if they had noticed any changes in the climate in recent years. Out of the 444 farmers interviewed, all but one answered in the affirmative. Respondents were then asked what form the changes in climate they had noticed took; and their responses are shown in Table 2 below.

Table2.Perceived changes in climate

\begin{tabular}{|l|l|l|}
\hline Observed Changes in Climate & Frequency & Percentage (\%) \\
\hline No observation made & 1 & 0.2 \\
\hline Long dry periods & 146 & 32.9 \\
\hline Unpredictable rainfall patterns & 123 & 27.7 \\
\hline High sunshine/ Temperatures & 100 & 22.5 \\
\hline Short rainfall period & 74 & 16.7 \\
\hline Total & 444 & 100 \\
\hline
\end{tabular}

Source: Field Survey, 2013

The results indicated that $33 \%$ of the farmers perceived that there was a longer dry period than before. An unpredictable rainfall pattern was another way in which the change had been noticed by another $28 \%$ of the farmers interviewed. To them, the total amount of rainfall might not have changed; but the timing of the rains was either earlier or later than expected. A hundred $(22 \%)$ of the farmers had observed both increases in temperatures and sunshine, while the remaining nearly $17 \%$ said the rainfall season had become shorter than usual. They further added that the number of rainfall events during the rainy season had decreased consistently; and the number of heavy rain events during the rainy season as well as the total amount of rainfall had decreased.

Farmers single out rainfall as the single most important climatic variable which has significantly changed over the past few decades and has had an impact on their cropping system. This supports Adjei-Nsiah\&Kermah's (2012)[6] findings that a significant number of farmers considered a shortened rainy season and frequent droughts as the most significant indicators of climate change. 
Cocoa Farmers and their Perceptions of Climate Change: A Case Study of the Central and Western Regions of Ghana

The farmers were also asked to indicate how they perceived some of the climate indicators - whether there had been an increase, a decrease or there had been no change in their observations. The results are presented in Table 3.

Table3.Farmers observation of climatic occurrences

\begin{tabular}{|l|l|l|l|l|}
\hline Climatic Occurrences & Increase (\%) & Decrease (\%) & No change (\%) & Total \\
\hline Temperature & $316(71.2 \%)$ & $21(4.7 \%)$ & $107(24.1 \%)$ & $444(100 \%)$ \\
\hline Precipitation & $33(7.4 \%)$ & $409(92.1 \%)$ & $2(0.5 \%)$ & $444(100 \%)$ \\
\hline Occurrence of Drought & $434(97.7 \%)$ & $9(2.0 \%)$ & $1(0.2 \%)$ & $444(100 \%)$ \\
\hline Late Onset of Monsoon & $363(81.7 \%)$ & $70(15.8 \%)$ & $11(2.5 \%)$ & $444(100 \%)$ \\
\hline Long Dry Spell & $409(92.1 \%)$ & $29(6.5 \%)$ & $6(1.4 \%)$ & $444(100 \%)$ \\
\hline Uneven Distribution of Rainfall & $414(93.2 \%)$ & $17(3.8 \%)$ & $13(2.9 \%)$ & $444(100 \%)$ \\
\hline Unpredictable Rainfall & $419(94.4 \%)$ & $9(2.0 \%)$ & $16(3.6 \%)$ & $444(100 \%)$ \\
\hline
\end{tabular}

Source: Field survey, 2013

With respect to temperature, while a majority $316(71.2 \%)$ said it had increased in recent times, compared with the past, a significant $107(24.1 \%)$ felt there had been no change in this element. The remaining $21(4.7 \%)$ felt that there had rather been a decrease in temperature. The observation of changes in temperature, unlike rainfall is usually difficult without appropriate measurements. Thus the varied views of cocoa farmers on changes in temperature are not surprising. The results in respect of precipitation, however, show a remarkable uniformity of opinion across the sample. The vast majority $409(92.1 \%)$ of the farmers believed that the rainfall levels had decreased. Furthermore, regarding the perception of changes in precipitation, nearly $98 \%$ of the farmers thought that the districts were getting drier and that there were pronounced changes in the timing of the rains and the frequency of droughts. A huge majority, 419(94.4\%) of the respondents also believed they had witnessed an uneven distribution and an unpredictable behaviour of the rains in recent years.

Farmers were also asked how long ago it was since they had noticed these changes. Table 4 below shows that, 105(23.6\%), 206 (46\%), 41 (9.2) and 91 (20.5\%) of the farmers had observed these changes in the past 1-2 years, 3-4 years, 5-6 years and more than 6 years respectively.

Table4.Number of Years since Climate Change Observations Were Made

\begin{tabular}{|l|l|l|}
\hline Number of Years & Frequency & Percentage $(\boldsymbol{\%})$ \\
\hline $1-2$ years & 105 & $23.6 \%$ \\
\hline $3-4$ years & 206 & $46.4 \%$ \\
\hline $5-6$ years & 41 & $9.2 \%$ \\
\hline More than 6 years ago & 91 & $20.5 \%$ \\
\hline Total & $\mathbf{4 4 4}$ & $\mathbf{1 0 0}$ \\
\hline
\end{tabular}

Source: Field Survey, 2013.

\subsection{Factors Affecting Farmer Perceptions of Climate Change}

The results of the analysis of the factors influencing a farmer's perception of climate change revealed that the age, farming experience, innovativeness, environmental consciousness, interaction with extension officers and exposure to the mass media had a positive and significant relationship with a farmer's perception of climate change. This means that the farmers best qualified to pronounce on whether climate change has occurred or not are those who have had the most experience in farming and are innovative, environmentally conscious and have exposure to the mass media.

The gender of the respondents also showed some correlation with their level of perception, implying that male farmers are more likely to perceive changes in climate than their female counterparts. This may be because usually males are more involved in cocoa farming activities than females who have other household duties to attend to.

Age as a factor which was positively correlated with the level of perception of the cocoa farmers, implies that the older the respondent, the higher the probability of his or her perceiving changes in climatic conditions. This finding on the effect of age on perception is in line with results reported by 
Deressa et al., 2008 and 2009[7\&8]. The general impression is that older farmers have greater experience in observing climatic changes over time. However, this may not be entirely correct since age does not necessarily connote experience in farming. How long one has been a farmer is a more appropriate variable. Farmers are likely to gain more experience in a particular crop as they farm over a period of time. No wonder there is a positive and significant correlation between farming experience and perception of climate change in the study area.

The level of education was also positively correlated to the perceptions of cocoa farmers of climate change. The implication is that highly educated farmers are more likely to perceive that climate is changing than uneducated ones. However, the correlation is weak, with a coefficient of only 0.03 .

Table5.Relationship between Independent Variables and Farmers Perception

\begin{tabular}{|l|l|}
\hline Independent Variables & 'r' value \\
\hline Farming Experience & $0.810^{*}$ \\
\hline Age & $0.41^{*}$ \\
\hline Education & 0.03 \\
\hline Environmental Consciousness & $0.45^{*}$ \\
\hline Contact with Extension Personnel & 0.022 \\
\hline Innovativeness & 0.215 \\
\hline Exposure to Mass Media & $0.424^{*}$ \\
\hline Gender & $0.441^{*}$ \\
\hline
\end{tabular}

*Significant at $5 \%$ probability level

\section{SUMmaRY, CONCLUSION AND RECOMMENDATION}

The results indicate that the vast majority (99.8\%) of the respondents in the study areas are aware of climate change issues. They perceive climate change in terms of changes in the rainfall pattern and in prolonged dry seasons. The respondents attributed the decline in cocoa production in the study area to climate change which brings about drought and an unpredictable rainfall pattern as experienced in the growing districts in recent years. Most of the farmers complained that they are unable to replant their dead cocoa farms due to high cocoa seedling mortality, the result of erratic rainfall and prolonged dry seasons. They indicated that the rainfall pattern over the past 3-5 years has been unstable. The high incidence of the black pod disease is also attributed to the excessive rainfall in the hitherto short dry period between July and August.

Also noteworthy is the fact that farmers can be influenced by their peers' perceptions and by values prevalent in their communities, as well as their professional associations. Hence, there is the need to carefully explore how farmers' choice of adaptation measures is influenced by socioeconomic as well as political characteristics so as to enable region-specific adaptation policies to be designed and implemented.

The issue of climate change is no longer the burden of government alone. Everybody must be a stakeholder in the struggle to combat its effects. On the basis of the findings of this study, it is recommended that policy makers should critically examine such factors as gender, educational level, age as well as farming experience in designing a holistic policy for sustaining adaptation measures by the farmers, since these factors affect their perception of climate change and hence their adaptation to it.

\section{REFERENCES}

[1] Maddison, D. (2006). The perception of and adaptation to climate change in Africa. CEEPA. Discussion Paper No. 10. Centre for Environmental Economics and Policy in Africa. Pretoria, South Africa: University of Pretoria.

[2] Bartley S.W. (1969). Principles of perception. New York: Harper Row PublishersForgus, R. H. (1966). Perception: the basic process in cognitive development. New York: Mcgraw-Hill. 
[3] Barnhart, R. K. (1988). The world book dictionary. Chicago: World Book Inc.Adu, S. V. \& MensahAnsah(1969). Classification of Ghanaian soils for cocoa rehabilitation. Proc. $3^{r d}$ Intl. Cocoa Res. Conf. Accra, 56-64.

[4] Adjei-Nsiah, S. \&Kermah, M. (2012). Climate change and shift in cropping system: from cocoa to maize based cropping system in Wenchi area of Ghana. British Journal of Environment \& Climate Change 2(2): 137-152, 2012.

[5] Deressa, T. T., Hassan, R. M., Alemu, T., Yesuf, M. \&Ringler, C. (2008).

[6] Analysing the determinants of farmers' choice of adaptation methods and perceptions of climate change in the Nile Basin of Ethiopia. IFPRI Discussion Paper 00798.

[7] Deressa, T. T., Hassan, R. M., Ringler, C., Alemu, T. \& Yusuf, M. (2009).

[8] Determinants of farmers' choice of adaptation methods to climate change in Nile Basin of Ethiopia. Global Environmental Change 19, 248-255.

Citation: Dr. David NiiBaah Buxton, et al., "Cocoa Farmers and their Perceptions of Climate Change: A Case Study of the Central and Western Regions of Ghana", International Journal of Research Studies in Agricultural Sciences, vol. 4, no. 3, p. 1-7, 2018. http://dx.doi.org/10.20431/2454-6224.0403001

Copyright: (C) 2018 Authors.This is an open-access article distributed under the terms of the Creative Commons Attribution License, which permits unrestricted use, distribution, and reproduction in any medium, provided the original author and source are credited. 